\title{
Inhibition of microbial biofilm formation by Cydonia oblonga Mill. fruit peel and leaf ethanolic extracts
}

\author{
Dejan Stojković ${ }^{1}$, Kristina JeVRemović ${ }^{1}$, MARIJA Smiljković ${ }^{1}$, Jelena Žıvković2,*, and \\ MARINA SOKOVIĆ ${ }^{1}$ \\ ${ }^{1}$ University of Belgrade, Institute for Biological Research "Siniša Stanković", Department of Plant Physiology, Bulevar Despota Stefana 142,11000 \\ Belgrade, Serbia. \\ 2 Institute for Medicinal Plant Research "Dr. Josif Pančić”, Tadeuša Košćuška 1, 11000 Belgrade, Serbia \\ *Corresponding author: jzivkovic@mocbilja.rs
}

\begin{abstract}
Biological activities of Sorbus aucuparia L. leaves extract were tested in our study. This study aimed to investigate the activity of $C y$ donia oblonga Mill. peels and leaf ethanolic extracts on biofilm formation of different microbial strains, including pathogenic bacteria and food poisoning strains. It was shown that both of the investigated extracts inhibited biofilm formation in a dose dependent manner with sub-minimal inhibitory concentrations. The percentage of biofilm formation inhibition varied for each bacterial strain and was in the range of $10-100 \%$, for both of the tested extracts. The ability of extracts to inhibit already formed biofilms presented as minimal concentration necessary to disrupt biofilms and concentrations was in the range of $10-100 \mu \mathrm{g} / \mathrm{mL}$ for the leaf extract and $5-75 \mu \mathrm{g} / \mathrm{mL}$ for the peel extract. The investigated extracts showed a promising antimicrobial effect comparable to, or even higher than the used reference compounds, which make these plant parts attractive for pharmaceutical and food industry.
\end{abstract}

Key words: Cydonia oblonga; peel; leaves; biofilm; antibacterial

http://dx.doi.org/10.5937/leksir1838058S

\section{INTRODUCTION}

Cydonia oblonga Mill. (quince), a plant of Rosaceae family is well known for its medicinal, nutritional, and ornamental uses (Ashraf et al., 2016). As a rich source of secondary metabolites (phenolic compounds, steroids, terpenoids, sugars, and organic acids) it possess a wide range of bioactivities (antioxidant, antibacterial, antifungal, anti-inflammatory, hepatoprotective, cardiovascular, antidepressant, antidiarrheal, hypolipidemic, diuretic, and hypoglycaemic). Although the ripe fruit of quince have a pleasant, lasting, and powerful flavour, consumption of fresh quince fruits is not widespread mainly due to excessive and aggressive astringency and sourness as well as woodiness (Griñán et al., 2019). Due to its hardness and acidity, it is not edible without prior processing (Griñán et al., 2019), but it is generally used for preparation of jam, jelly, liqueur, and marmalade, and it is applied in canning and for aromatic distillation (Baroni et al., 2018).

In nature, mostly of microorganisms, are organized in the form of biofilms, and about $80 \%$ of human infections are connected with the development of biofilms (Zijnge et al., 2010). The formation of biofilm may contain one or more species. It is often formed on organic or inorganic surfaces. The major component of biofilm is water (95\%) then extracellular matrix (1-2\%) and microorganisms (2-5\%). Biofilm's forming can be organized in three phases: annexation, maturation and dispersion (Williams and Cámara, 2009). Also depending on a number of factors, like a physical environmental factor or available food, there are three types of biofilm: heterogenous-mosaic type, and porous type which is intersected by water channels and thick-confluent type (Tolker-Nielsen, 2014). Infections caused by biofilms are considerably complicated, because these infections are asymptomatic.

This work aimed to investigate the activity of Cydonia oblonga Mill. peels and leaf ethanolic extracts on biofilm formation of different microbial strains, including pathogenic bacteria and food poisoning strains.

\section{MATERIALS AND METHODS}

\subsection{Sample collection and extract preparation}

Cydonia oblonga Mill. leaves and fruits were collected in Vranje, southern Serbia. Peels were separated from the fruits and further used for the experiments. The powdered fruit peels and leaves $(\sim 10 \mathrm{~g})$ were extracted by stirring with $300 \mathrm{~mL}$ of ethanol, at room temperature, $150 \mathrm{rpm}$, for $24 \mathrm{~h}$. The extract was filtered through Whatman No. 4 paper. The residue was then re-extracted twice with additional portions $(300 \mathrm{~mL})$ 
Table 1. Minimal inhibitory (MIC), minimal bactericidal (MBC) and fungicidal concentrations (MFC) of C. oblonga extracts $(\mu \mathrm{g} / \mathrm{mL})$ that influenced biofilms

\begin{tabular}{lrrrrrrrrrrrr}
\hline MO strain & \multicolumn{2}{c}{ Peel extract } & \multicolumn{2}{c}{ Leaf extract } & \multicolumn{3}{c}{ Ampicilin } & \multicolumn{2}{c}{ Streptomycin } & Miconazole \\
& MIC & MBC (MFC) & MIC & MBC (MFC) & MIC & MBC & MIC & MBC & MIC & MFC \\
\hline S. aureus & 10 & 20 & 5 & 10 & 100 & 150 & 250 & 500 & - \\
L. monocytogenes & 20 & 20 & 10 & 20 & 150 & 300 & 150 & 300 & - & - \\
P. aeruginosa & 80 & 100 & 60 & 75 & 100 & 200 & 50 & 100 & - & - \\
E. coli & 40 & 80 & 20 & 20 & 300 & 500 & 50 & 100 & - \\
S. typhimurium & 100 & 100 & 50 & 75 & 150 & 200 & 50 & 100 & - \\
C. albicans & 60 & 80 & 40 & 60 & - & - & - & - \\
\hline
\end{tabular}

of ethanol. The combined extracts were evaporated at $45^{\circ} \mathrm{C}$ (rotary evaporator Büchi R-210, Flawil, Switzerland) to remove ethanol.

\subsection{Microorganisms}

The microorganisms tested included 5 bacterial: Gramnegative bacteria Escherichia coli (ATCC 35210), Pseudomonas aeruginosa (ATCC 27853), and Salmonella typhimurium (ATCC 13311), Gram-positive bacteria Listeria monocytogenes (NCTC 7973) and Staphylococcus aureus (ATCC 6538), and a yeast Candida albicans (ATCC 10231). The species were maintained in Mueller Hinton Agar and Trptone Soy Agar (MHA, TSA, Torlak, Serbia). The organisms were obtained from the Mycological Laboratory, Department of Plant Physiology, Institute for Biological Research "Siniša Stanković", Belgrade, Serbia.

\subsection{Biofilm susceptibility test}

The effect of peels and leaves ethanolic extracts of C. oblonga on the biofilm were determined as previously described by Pierce et al. (2008), with some modifications. Briefly, fresh overnight cultures of bacteria and yeast were harvested from liquid cultures for cells and re-suspended for suspensions of 1 $\times 106$ cells $/ \mathrm{mL}$ final density. Biofilms were formed in 96-well polystyrene flat bottom TC treated microtitre plates (Sarstedt, North Carolina, USA). The plates were incubated at $37{ }^{\circ} \mathrm{C}$ for $48 \mathrm{~h}$ to allow biofilm formation. The culture media was removed, and the wells were washed three times with saline solution to remove the non-adhered cells. The extracts solution $(200 \mu \mathrm{L})$ was added to the wells. The microplates were incubated at $37^{\circ} \mathrm{C}$ for $24 \mathrm{~h}$. Three repetitions were performed. After $24 \mathrm{~h}$ at $37^{\circ} \mathrm{C}$, biofilm reduction was determined by following staining process and measuring the UV absorbance of stains at $620 \mathrm{~nm}$ using a plate reader. MIC was defined as the minimum concentration of antimicrobial agent that inhibited further growth of the initial biofilm, and MBC was defined as the concentration that resulted in level of luminescence presenting no bacterial growth (empty well).

\subsection{Inhibition of biofilm formation}

Biofilm was grown as described previously. The effect of different concentrations of the extract (ranging from 5 to $125 \mu \mathrm{g} / \mathrm{mL}$ of MIC) on biofilm forming ability was tested on polystyrene flat-bottomed microtitre 96 well plates as described (Pierce et al., 2008), with some modifications. Briefly, $100 \mu \mathrm{L}$ of overnight cultures were added to each well of the plates in the presence of $100 \mu \mathrm{L}$ sub-inhibitory concentrations (subMIC) of the extracts $(0.5,0.25$ and $0.125 \mathrm{mg} / \mathrm{mL}$ MIC) or $100 \mathrm{~mL}$ medium (control). After incubation for $24 \mathrm{~h}$ at $37^{\circ} \mathrm{C}$, each well was washed twice with sterile PBS (pH 7.4), dried, and stained for $10 \mathrm{~min}$ with $0.1 \%$ crystal violet in order to determine the biofilm mass. After drying, $200 \mu \mathrm{L}$ of $95 \%$ ethanol (v/v) was added to solubilize the dye that had stained the biofilm cells. The excess stain was washed off with $\mathrm{dH}_{2} \mathrm{O}$. After $10 \mathrm{~min}$, the content of the wells was homogenized and the absorbance at $\lambda=625 \mathrm{~nm}$ was read on a Sunrise ${ }^{\mathrm{TM}}-$ Tecan ELISA reader.

\section{RESULTS AND DISCUSSION}

It is well known that biofilm forming pathogens are essential for severe infections which are commonly very difficult to treat. This is due to the high resistance of biofilms to antibiotics, antiseptics and disinfectants as well as to host defence mechanisms (Rozalski et al., 2013). Therefore, biofilms present severe problems for food and healthcare industries.

In our study the ability of extracts to inhibit already formed biofilms was presented as minimal concentration necessary to disrupt biofilms and these concentrations were in the range of $10-100 \mu \mathrm{g} / \mathrm{mL}$ for the leaf extract and $5-75 \mu \mathrm{g} / \mathrm{mL}$ for the peel extract (Table 1). For most of the bacterial strains investigated extracts showed significantly higher activity compared to the used standard compounds. Namely, commercial antibiotics ampicillin and streptomycin showed bacteriostatic activity in the range of 50 to $250 \mu \mathrm{g} / \mathrm{mL}$, and bactericidal activity in the range of 100 to $500 \mathrm{mg} / \mathrm{mL}$.

In test of microplate biofilm formation of microorganisms, leaf extract was more effective among the two tested extracts, and its MIC and MBC values were lowest against Staphylococcus aureus $(\mathrm{MIC}=5 \mu \mathrm{g} / \mathrm{mL}$ and $\mathrm{MBC}=10 \mu \mathrm{g} / \mathrm{mL}$ ). The most resistant microbial biofilm was the one formed by Pseudomonas aeruginosa (MIC and MBC values were $60 \mu \mathrm{g} / \mathrm{mL}$ and $75 \mu \mathrm{g} / \mathrm{mL}$, respectively). As for the ethanolic extract obtained from the peel of C. oblonga, the most resistant biofilm was the one formed by Salmonella typhimurium, while once again Staphylococcus aureus was the most sensitive strain (results in Table 1).

The effects of peel and leaf extracts on the biofilm growth of $S$. aureus, L. monocytogenes, $P$. aeruginosa, E. coli and C. albicans were tested with concentrations of the extracts equal to 0.500 , $0.125,0.062$ and 0.031 parts of the determined MIC values. It was shown that both of the tested extracts inhibited biofilm formation with sub-minimal inhibitory concentrations. The percentage of biofilm inhibition was variable for each species and was in range of $5-100 \%$, for both of the extracts (Tables 2 and 3). Biofilm formation was in both cases completely inhibited at MIC concentration, while in cases of applied concentrations of 1/16 MIC and in all cases 1/32 MIC the biofilm was not inhibited in comparison to the control. Among these two extracts, again sub-MIC concentrations of leaf extract were more effective and had higher percentages of inhibition. The antibacterial effects of the leaves of $C$. oblonga extracts have been poorly investigated to date. Fattouch et al. (2007) stated that chlorogenic acids and rutin are dominant phenolic compounds in the peel of quince and these compounds showed 
Table 2. Inhibition of biofilm formation by C. oblonga leaf extract

\begin{tabular}{lrrrrrr}
\hline & $\begin{array}{r}\text { mic }^{\mathrm{a}} \\
{[\%]}\end{array}$ & $\begin{array}{r}1 / 2 \mathrm{mic} \\
{[\%]}\end{array}$ & $\begin{array}{r}1 / 4 \mathrm{mic} \\
{[\%]}\end{array}$ & $\begin{array}{r}1 / 8 \mathrm{mic} \\
{[\%]}\end{array}$ & $\begin{array}{r}1 / 16 \mathrm{mic} \\
{[\%]}\end{array}$ & $\begin{array}{r}1 / 32 \mathrm{mic} \\
{[\%]}\end{array}$ \\
\hline S. aureus & $\mathrm{NB}$ & 67.0000 & 74.9000 & 78.7400 & 55.0600 & $\mathrm{NI}$ \\
L. monocytogenes & $\mathrm{NB}$ & 74.8691 & 76.6143 & 73.4729 & 24.6073 & $\mathrm{NI}$ \\
Ps. aeruginosa & $\mathrm{NB}$ & 86.8201 & 89.7490 & 90.1674 & 74.6862 & $\mathrm{NI}$ \\
E. coli & $\mathrm{NB}$ & 84.1450 & 87.3160 & 86.7497 & $\mathrm{NI}$ & $\mathrm{NI}$ \\
S. typhimurium & $\mathrm{NB}$ & 83.1254 & 79.2145 & 43.2510 & $\mathrm{NI}$ & $\mathrm{NI}$ \\
C. albicans & $\mathrm{NB}$ & 37.6106 & 31.4159 & 5.3097 & $\mathrm{NI}$ & $\mathrm{NI}$
\end{tabular}

${ }^{\mathrm{a}} \mathrm{NB}$ - no biofilm is formed; NI - no inhibition

Table 3. Inhibition of biofilm formation by C. oblonga peels extract

\begin{tabular}{|c|c|c|c|c|c|c|}
\hline & $\begin{array}{r}\mathrm{mic}^{\mathrm{a}} \\
{[\%]}\end{array}$ & $\begin{array}{r}1 / 2 \mathrm{mic} \\
{[\%]}\end{array}$ & $\begin{array}{r}1 / 4 \mathrm{mic} \\
{[\%]}\end{array}$ & $\begin{array}{r}1 / 8 \mathrm{mic} \\
{[\%]}\end{array}$ & $\begin{array}{r}1 / 16 \mathrm{mic} \\
{[\%]}\end{array}$ & $\begin{array}{r}1 / 32 \mathrm{mic} \\
{[\%]}\end{array}$ \\
\hline S. aureus & NB & 62.0000 & 72.4200 & 42.1000 & 24.0620 & NI \\
\hline L. monocytogenes & NB & 80.2514 & 82.3578 & 74.6582 & 44.2517 & NI \\
\hline Ps. aeruginosa & NB & 84.2144 & 88.2143 & 88.4579 & 72.4795 & NI \\
\hline E. coli & NB & 87.6316 & 89.4148 & 89.7689 & 30.2145 & NI \\
\hline S. typhimurium & NB & 78.2142 & 72.2145 & 41.2153 & 20.6457 & NI \\
\hline C. albicans & NB & 46.5617 & 21.4164 & 11.6792 & NI & NI \\
\hline
\end{tabular}

${ }^{\text {a }} \mathrm{NB}$ - no biofilm is formed; NI - no inhibition

significant antimicrobial activity against Pseudomonas aeruginosa, Escherichia coli, Staphylococcus aureus and Candida albicans. Karar et al. (2014) showed that C. oblonga fruit is a rich source of polyphenols including chlorogenic acids, proanthocyanidins and flavonol $\mathrm{C}$ - and $\mathrm{O}$-glycosides. Also, same authors showed that $C$. oblonga fruits possess significant antibacterial activity against $E$. coli which is in accordance with its traditional use as a food preservative. According to previous results the content of polyphenols in quince leaves is higher compared to some other plant parts, and tannins can make $17 \%$ of the total content. This group of compounds possess significant antibacterial activity against certain microorganisms such as S. aureus, E. coli and S. epidermids, due to ability to precipitate microbial proteins and to make nutritional proteins inaccessible for them (Cerempei et al., 2016).

\section{CONCLUSION}

In the present study we have demonstrated for the first time antibiofilm potential of the quince leaf and peel extracts. The investigated extracts showed a promising antimicrobial effect comparable to, or even higher than the used reference compounds, which makes these plant parts also attractive for pharmaceutical and food industry.

\section{ACKNOWLEDGMENTS}

Acknowledgment. This work has been supported by the Serbian Ministry of Education, Science and Technological Development with financial support (Grant numbers OI173032, III46013 and TR31089).

\section{REFERENCES}

Ashraf, M. U., Muhammad, G., Hussain, M. A. and Bukhari, S. N. A. (2016). Cydonia oblonga M., A Medicinal Plant Rich in Phytonutrients for Pharmaceuticals, Frontiers in Pharmacology 7.

Baroni, M. V., Gastaminza, J., Podio, N. S., Lingua, M. S., Wunderlin, D. A., Rovasio, J. L., Dotti, R., Rosso, J. C., Ghione, S. and Ribotta, P. D. (2018). Changes in the Antioxidant Properties of Quince Fruit ( Cydonia oblonga Miller) during Jam Production at Industrial Scale, Journal of Food Quality 2018: 1-9.

Cerempei, A., Mureşan, E. I., Cimpoeşu, N., Carp-Cărare, C. and Rimbu, C. (2016). Dyeing and antibacterial properties of aqueous extracts from quince (Cydonia oblonga) leaves, Industrial Crops and Products 94: 216-225.

Griñán, I., Galindo, A., Rodríguez, P., Morales, D., Corell, M., Centeno, A., Collado-González, J., Torrecillas, A., CarbonellBarrachina, A. and Hernández, F. (2019). Volatile composition and sensory and quality attributes of quince ( Cydonia oblonga Mill.) fruits as affected by water stress, Scientia Horticulturae 244: 68-74.

Karar, M. G. E., Pletzer, D., Jaiswal, R., Weingart, H. and Kuhnert, N. (2014). Identification, characterization, isolation and activity against Escherichia coli of quince (Cydonia oblonga) fruit polyphenols, Food Research International 65: 121-129.

Pierce, C. G., Uppuluri, P., Tristan, A. R., Wormley, F. L., Mowat, E., Ramage, G. and Lopez-Ribot, J. L. (2008). A simple and reproducible 96-well plate-based method for the formation of fungal biofilms and its application to antifungal susceptibility testing, Nature Protocols 3(9): 1494-1500.

Tolker-Nielsen, T. (2014). Pseudomonas aeruginosa biofilm infections: From molecular biofilm biology to new treatment possibilities, APMIS 122: 1-51. 
Williams, P. and Cámara, M. (2009). Quorum sensing and environmental adaptation in Pseudomonas aeruginosa: a tale of regulatory networks and multifunctional signal molecules, Current Opinion in Microbiology 12(2): 182-191.

Zijnge, V., van Leeuwen, M. B. M., Degener, J. E., Abbas, F., Thurnheer, T., Gmür, R. and M. Harmsen, H. J. (2010). Oral Biofilm Architecture on Natural Teeth, PLOS ONE 5(2): e9321. 